\title{
FONEM KONSONAN DAN VOKAL BAHASA BALI DI KABUPATEN TABANAN: KAJIAN DIALEKTOLOGI STRUKTURAL
}

\author{
I Ketut Subagia \\ Universitas Warmadewa \\ ketutsubagia226@gmail.com \\ Dewa Ayu Dyah Pertiwi Putri \\ Universitas Warmadewa \\ dyahpertiwiputridewaayu@gmail.com
}

\begin{abstract}
ABSTRAK
Penelitian ini bertujuan untuk mengetahui variasi fonologi bahasa Bali di Kabupaten Tabanan dan pemetaannya. Pengamatan dilakukan di empat desa, yakni Desa Bongan, Desa Berembeng, Desa Sanda, dan Desa Wangaya Gede. Data dikumpulkan dengan menggunakan metode cakap dan metode simak. Data merupakan kata-kata swadesh yang diujarkan oleh informan selama wawancara. Adapun hasil yang diperoleh adalah Fonem /ə/ pada posisi akhir terbuka memiliki dua buah realisasi yaitu bunyi [a] dan bunyi [ə]. Masing-masing bunyi tersebut memiliki areal yang berbeda. Bunyi [ə] terdapat di titik pengamatan 1,2,4 dan bunyi [a] terdapat di titik pengamatan 3. Fonem /e/ pada posisi

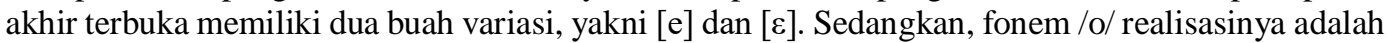
[o] dan [o]. Bunyi [e] dan [o] terdapat di titik pengamatan 1,2,4 dan bunyi $[\varepsilon]$ dan [0] terdapat pada TP 3. Di samping perbedaan realisasi fonem vokal, terdapat pula perbedaan realisasi fonem konsonan /k/. Fonem /k/ direalisasikan dengan [k] dan [?]. Bunyi [k] direalisasikan pada TP 3, sedangkan [?] direalisasikan pada TP 1,2,4. TP 1,2,4 tidak memiliki fonem /a/ pada distribusi akhir, sedangkan TP 3 memiliki distribusi /a/ yang lengkap. Pada daerah yang memiliki fonem /a/ dengan distribusi lengkap, tidak dikenal bunyi [ə] pada distribusi akhir. Pada daerah-daerah yang memiliki fonem /a/ berdistribusi tidak lengkap, bunyi [ə] justru berdistribusi lengkap. Bunyi [k] pada distribusi akhir tidak dikenal pada TP 3, bunyi itu hanya dikenal pada distribusi terakhir di TP 1,2,4. Bunyi [?] pada distribusi akhir dikenal pada TP 1,2,4 dan tidak dikenal pada TP 3.
\end{abstract}

Kata kunci: fonem; konsonan; vokal; Dialektologi

\begin{abstract}
This study aims to investigate the phonological variations of the Balinese language in Tabanan Regency and to map them. Observations were made in four villages, namely Bongan, Berembeng, Sanda, and Wangaya Gede. Data were collected by using interview and observation methods. The data are swadesh words spoken by the informants during the interview. The results obtained were that the phoneme / $/ \mathrm{d} /$ in the final open position has two realizations, namely [a] and [ə]. Each sound has a different area. [a] found at the observation point 1,2,4 and [a] found at the observation point 3. The phoneme le/ at the open end position has two variations, namely [e] and [8], while the phoneme $10 /$ realized by [o] and [o]. [e] and [o] were found at the observation point 1,24 , while [ $\varepsilon$ ] and [o] were found in TP 3. In addition, there was also difference in the realization of the $\mathrm{k} / \mathrm{k}$ consonant phoneme. The phoneme $/ k /$ is realized by [k] and [?]. [k] was used in TP3, while [?] used in TP 1,2,4. In TP 1,2,4 there was not phoneme /a/ in the final distribution, while TP 3 has a complete la/ distribution. Areas that have a complete phoneme la/ distribution, [a] would not be found in the final distribution. In areas where the phoneme /a/ has incomplete distribution, [o] has a complete distribution there. $[k]$ in the final distribution was unknown at TP3, but known in TP 1,2,4. Meanwhile [?] in the final distribution was known merely in TP 1,2,4 but not in TP 3.
\end{abstract}

Keywords: phoneme; consonant; vowel; Dialectology 


\section{PENDAHULUAN}

Bahasa Bali sebagai bahasa Ibu bagi masyarakat Bali memiliki variasi baik secara geografis maupun secara stratifikasi sosial. Bahasa Bali tidak hanya berfungsi sebagai alat komunikasi, tetapi juga dijadikan sebagai identitas dan jadi diri bagi masyarakat Bali. Para penutur bahasa Bali umumnya adalah mereka yang mengusung budaya Bali. Penutur bahasa Bali tidak hanya berada di Pulau Bali. Penutur bahasa Bali ada juga di Nusa Tenggara Barat, dan daerah lain yang dihuni transmigran asal Bali, seperti Lampung, Sulawesi Tenggara, dan Kalimantan Tengah.

Secara umum, bahasa Bali yang ada di Bali dibagi menjadi dua dialek, yaitu Dialek Bali Dataran dan Dialek Bali Aga. Kedua dialek ini tetap dipelihara dan digunakan sebagai alat komunikasi aktif antarpenutur dalam kehidupan sehari-hari.

Bahasa Bali di Kabupaten Tabanan termasuk dalam Dialek Bali Dataran. Walaupun termasuk Dialek Bali Dataran, bukan berarti bahasa Bali (BB) di Kabupaten Tabanan adalah bahasa Bali baku. Bahasa Bali yang dituturkan oleh masyarakat Kabupaten Tabanan dianggap BB yang tidak baku. Hal ini mungkin disebabkan oleh lafal BB di Kabupaten Tabanan agak berbeda dengan lafal-lafal penutur dari tiga kabupaten yang dianggap baku. Bahasa Bali yang dianggap baku adalah BB yang digunakan di Kabupaten Buleleng, Karangasem, dan Klungkung (Jendra, I Wayan, 1977: 191). Di samping itu, BB yang dianggap baku adalah adalah BB yang digunakan dalam pendidikan, karya tulis, rapat, media masa, agama, dan sebagainya (Bagus, 1975: 46). Hal ini berarti selain ketiga kabupaten tersebut, BB di kabupaten lainnya termasuk dalam BB tidak baku.

Jika ilmu bahasa pada umumnya memerhatikan gejala-gejala keumuman yang terdapat dalam setiap bahasa, dialektologi justru sebaliknya. Tampaknya masalah baku atau tidaknya suatu bahasa memerhatikan gejala bahasa secara umum. Dialektologi memerhatikan keanekaragaman unsur-unsur bahasa yang disebabkan oleh beberapa faktor. Penyebab utamanya adalah penutur yang memiliki perbedaan asal, jenis kelamin, umur, dan pendidikan. Oleh karena itu, bahasa Bali di Kabupaten Tabanan yang merupakan salah satu
BB tidak baku sangat cocok dijadikan objek penelitian dialektologi.

Penelitian ini ditujukan untuk mengetahui bagaimana variasi fonologi BB di Kabupaten Tabanan dan bagaimana pemetaan variasi fonologi BB di Kabupaten Tabanan.

\section{METODE}

Metode dan teknik yang dipakai dalam penelitian ini, dibedakan menjadi tiga, yaitu (1) metode dan teknik pengumpulan data, (2) metode dan teknik Analisis data, dan (3) metode dan teknik penyajian hasil analisis.

Dalam pengumpulan data digunakan metode pupuan lapangan. Penggunaan metode ini dianggap efektif karena dapat menghasilkan data primer. Data dikumpulkan dengan dua cara, yaitu (1) pencatatan langsung dan (2) perekaman. Disamping itu, digunakan juga metode cakap dan simak (Sudaryanto, 2015). Metode cakap dilaksanakan dengan menggunakan daftar kosa kata swadesh yang telah dipersiapkan, sedangkan metode simak digunakan untuk menyimak pemakaian katakata yang diucapkan oleh informan sebagai jawaban dari kosa kata yang ditanyakan. Pemakaian metode tersebut didukung dengan teknik pancing dan teknik sadap berupa teknik rekam dan teknik catat selama berlangsungnya wawancara (Ayatrohaedi, 1979: 33) (Sudaryanto, 2015).

Dalam tahap analisis digunakan metode dialektologi dengan cara kerja mengomparasikan unsur-unsur BB di Tabanan berdasarkan data yang telah terkumpul. Karena pembahasannya menitikberatkan pada bidang fonologi, unsur yang dibandingkan adalah unsur yang menyangkut tataran fonologi saja. Sedangkan dalam penyajian hasil analisis, digunakan metode informal dibantu dengan metode formal. Metode informal yaitu penyajian kaidah berupa perumusan dengan kata-kata biasa, sedangkan metode formal adalah penyajian kaidah berupa perumusan dengan tanda dan lambang: seperti peta, tanda kurung, dan diagram (Sudaryanto, 1982: 16-18) (Sudaryanto, 2015).

Untuk mendapatkan gambaran tetang pemakaian BB di Kabupaten Tabanan, diambil hanya empat titik pengamatan. Keempat titik pengamatan itu adalah Desa Bongan sebagai titik pengamatan 1 (TP1), Desa Berembeng 
sebagai TP 2, Desa Sanda sebagai TP 3, dan Desa Wangaya Gede sebagai TP 4. Informasi yang didapatkan dari empat titik pengamatan ini diharapkan dapat memberikan gambaran tentang fonologi BB di Kabupaten Tabanan.

\section{PEMBAHASAN}

\section{Fonologi Bahasa Bali Baku}

Fonologi bahasa Bali telah dibicarakan oleh Jendra dalam buku "Fonologi Bahasa Bali”. Buku ini merupakan satu-satunya buku yang membicarakan fonologi $\mathrm{BB}$ secara mengkhusus. Bahasa Bali mempunyai dua fonem segmental, yaitu fonem vokal dan fonem konsonan. Fonem vokal adalah bunyi bahasa yang pada waktu pembentukannya udara yang keluar dari paru-paru tidak mendapat halangan. Bahasa Bali mempunyai enam buah fonem vokal yaitu / i, e, a, ə, u, o /. Empat di antara enam fonem itu memiliki realisasi yang bervariasi, yakni fonem / i / dengan realisasinya [i] dan [I], fonem / u / dengan realisasinya [u] dan [ซ], fonem / e / dengan realisasinya [e] dan $[\varepsilon]$, fonem / o / dengan realisasinya [o] dan [o].

Fonem konsonan adalah bunyi-bunyi yang dihasilkan dengan cara menghambat udara yang keluar dari paru-paru via artikulator. Bahasa Bali baku mempunyai delapan belas fonem konsonan yaitu: / p, b, m, w, n, t, d, s, r, l, c, j, n, y, k, g, y, h/

\section{Fonem-Fonem Vokal Bahasa Bali di Kabupaten Tabanan}

Untuk mencari fonem-fonem suatu bahasa biasanya digunakan prinsip penentuan fonemfonem. Ada lima dalil atau lima prinsip dalam penentuan fonem-fonem suatu bahasa (Thoir \& Simpen, 1987: 105-106). Adapun prinsip itu adalah:

a) Bunyi-bunyi bahasa yang secara fonetis mirip apabila berada dalam pasangan minimal merupakan fonem sendiri-sendiri.

b) Bunyi-bunyi bahasa yang secara fonetis mirip apabila berdistribusi komplementer merupakan sebuah fonem.

c) Bunyi-bunyi bahasa yang secara fonetis mirip apabila bervariasi bebas merupakan sebuah fonem.

d) Bunyi-bunyi bahasa yang secara fonetis mirip apabila berada dalam pasangan mirip merupakan sebuah fonem sendirisendiri. e) Setiap bunyi bahasa yang berdistribusi lengkap merupakan sebuah fonem.

Dalam penentuan fonem vokal bahasa Bali di Kabupaten Tabanan hanya akan digunakan prinsip a), b), dan prinsip c).

Setelah dianalisis dengan menggunakan ketiga prinsip di atas ternyata jumlah fonem vokal BB di Kabupaten Tabanan sama dengan jumlah fonem vokal BB baku, yaitu enam buah. Adapun fonem-fonem itu adalah: / i, e, a, ə, u, o /. Beberapa data yang memiliki pasangan minimal dan berdistribusi komplementer disajikan berikut ini.

1) [lima] 'tangan'

2) [ilih] 'kipas'

3) [ikoh] 'ekor'

4) [Intø?] 'tumbuk'

5) [adcn] 'pelan'

6) [sate] 'sate'

7) [sclə] 'pelan'

8) [tuke] 'tokek'

9) [adcn] 'pelan'

10) [sərə] 'terasi'

11) [sere] 'juling'

12) $[\mathrm{lək}]$ 'malu'

13) [lkk] 'jari manis'

14) [alat] 'alat'

15 [alit] 'kecil'

16) [alih] 'cari'

17) [batu] 'batu'

18) [but?] 'buta'

19) [təgul] 'ikat'

20) [adv?] 'aduk'

21) [toko] 'toko'

23) [moksh] 'gemuk'

22) [bolon] 'lobang'

Bunyi vokal [i] dan [I] secara fonetis mirip, berdasarkan data 1) - 4) kedua bunyi itu berada dalam distribusi komplementer, [i] selalu berada pada suku terbuka dan [I] selalu berada pada suku tertutup. Oleh karena itu, kedua bunyi itu merupakan satu fonem yaitu /i/. Bunyi lain yang berada dalam distribusi komplementer ialah bunyi [u] dan [ひ]. Hal ini tampak pada data 17) - 20). Bunyi vokal [e], dan $[\varepsilon]$ juga secara fonetis mirip, kedua bunyi ini bervariasi bebas. Hal ini terbukti dari data 6) [sate] 'sate' akan tetap artinya jika dilafalkan dengan [sate] 'sate', ataupun [sat $\varepsilon$ ] 'sate'. Oleh karena itu, sesuai dengan prinsip c) bunyi-bunyi itu termasuk satu fonem, yaitu fonem /e/. Bunyi-buyi lain yang berada dalam variasi bebas adalah [ə] dan [e] serta bunyi [o], [O], dan [०]. Sesuai dengan prinsip c) bunyi-bunyi itu termasuk fonem yang sama, yaitu fonem /a/ dan fonem $/ \mathrm{o} /$. Sedangkan, bunyi [a] dan [i] berada dalam pasangan minimal, yakni data 2) [illh] 'kipas' dan data 16) [alIh] 'cari'. Oleh karena itu, kedua bunyi itu merupakan fonem tersendiri. 
Distribusi Fonem-Fonem Vokal Bahasa Bali di Kabupaten Tabanan

Distribusi fonem vokal BB di kabupaten Tabanan berikut mencerminkan realisasi dari tiap-tiap fonem vokal BB di kabupaten Tabanan.

Fonem /i/

Posisi awal:

ibi [ibi] 'kemarin' (TP 1,2,3,4)

ikuh [ikvh] 'ekor' (TP 1,2,3,4)

Posisi tengah:

gigi [gigi] 'gigi' (TP 1,2,3,4)

lima [lima] 'tangan' (TP 3)

Posisi Akhir:

sampi [sampi] 'sapi'(TP 1,2,3,4)

tali [tali] 'tali' (TP 1,2,3,4)

Fonem /e/

Posisi awal:

elah [Elah] 'gampang' (TP 1,2,3,4)

enggal [cygal] 'cepat' (TP 1,2,3,4)

Posisi tengah:

belek [bele?] 'lembek' (TP 1,2,3,4)

tenges[tencs] 'ingus' (TP 1,2,3,4)

Posisi Akhir:

bale[bale]'rumah' (TP 1,2,3,4)

rare [rare] 'bayi' (TP 1,2,4)

Fonem /a/

Posisi awal:

akah [akah] 'akar' (TP 1,2,3,4)

alih [alıh] 'cari' (TP 1,2,3,4)

Posisi tengah:

batis [batıs] 'kaki' (TP 1,2,3,4)

tanah[tanah] 'tanah' (TP 1,2,3,4)

Posisi Akhir:

lima[lima] 'tangan'(TP 3)

sida [sida] 'luka' (TP 3)

Fonem / ə /

Posisi awal:

ebek [əbək] 'penuh' (TP 1,2,3,4)

engsap [əysap] 'lupa' (TP 1,2,3,4)

Posisi tengah:

belah [bəlah] 'pecah' (TP 1,2,3,4)

telu[təlu] 'tiga' (TP 1,2,3,4)

Posisi Akhir:

sere[sərə] 'terasi'(TP 1,2,4)

side[sidə] 'luka' (TP 1,2,4)
Fonem / u /

Posisi awal:

ubad [ubad] 'obat' (TP 1,2,3,4)

umah [umah] 'rumah' (TP 1,2,3,4)

Posisi tengah:

bulan [bulan] 'bulan' (TP 1,2,3,4)

jukut [jukot] 'sayur' (TP 1,2,3,4)

Posisi Akhir:

bulu [bulu] 'bulu'(TP 1,2,3,4)

sidu [sidu] 'sendok dari daun'(TP 1,2,3,4)

Fonem / o /

Posisi awal:

ombak [ombak] 'ombak' (TP 1,2,3,4)

oles [oles] 'poles' (TP 1,2,3,4)

Posisi tengah:

bolong [bolon] 'lobang' (TP 1,2,3,4)

tomat [tomat] 'tomat' (TP 1,2,4)

Posisi Akhir:

daro [daro] 'burung dara' (TP 1,2,4)

toko [toko] 'toko' (TP 1,2,4)

Setelah diamati distribusi fonem-fonem vokal di atas, tampak ada variasi antara TP 1, 2, 4 dengan TP 3. Untuk lebih jelasnya, variasi bunyi yang terjadi antara TP 1, 2, 4 dengan TP3 disajikan sebagai berikut.

$\begin{array}{ll}\text { TP 1,2,4 } & \text { TP 3 } \\ \text { [bale] } & \text { [bal }] \\ \text { [gəde] } & \text { [gəd } \varepsilon] \\ \text { [rame] } & \\ \text { [ram }] & \\ \text { [radio] } & \\ \text { [radio] } & \\ \text { [nanko] } & \text { [nayko] } \\ \text { [limə] } & \text { [lima] } \\ \text { [sidə] } & \text { [sida] }\end{array}$

Pada masing-masing titik pengamatan, fonem vokal menunjukkan jumlah dan jenis yang sama. Jenis dan jumlah ini sama dengan yang ada dalam BB baku, yaitu enam buah fonem vokal. Hanya saja fonem /e/ dan /o/ pada posisi final di TP 3 direalisasikan dengan $[\varepsilon]$ dan [o], sedangkan di titik pengamatan lainnya direalisasikan dengan /e/ dan /o/.

Gambar 1. Peta variasi realisasi fonem /ə,e,o/

\begin{tabular}{|cc|}
\hline Tipe A (TP 3) & Tipe B (TP 1,2,4) \\
1) $[\mathrm{a}]$ & 1 ) [ə] \\
2) $[\varepsilon]$ & $2)[\mathrm{e}]$ \\
3) $[\mathrm{o}]$ & 3 ) [o] \\
\hline
\end{tabular}

Di samping memiliki perbedaan realisasi BB di kabupaten Tabanan juga memiliki 
perbedaan distribusi fonem. Bunyi [a] pada distribusi akhir hanya terdapat pada titik pengamatan 3, sedangkan bunyi [ə] pada posisi akhir terdapat pada titik pengamatan 1, 2 dan 4. Variasi distribusi fonem vokal dalam BB di kabupaten Tabanan diklasifikasikan menjadi dua tipe yaitu tipe A dan tipe B. Tipe A adalah daerah yang memiliki kelengkapan distribusi bunyi [a] dan tipe $\mathrm{B}$ adalah daerah-daerah yang memiliki kelengkapan distribusi bunyi [ə].

\section{Fonem-Fonem Konsonan Bahasa Bali di Kabupaten Tabanan}

Untuk menemukan fonem konsonan BB di kabupaten Tabanan, digunakan prinsip yang sama dengan penemuan fonem vokal, yaitu pasangan minimal, distribusi komplementer, variasi bebas, dan pasangan mirip. Dari data yang terkeumpul diketahui bahwa BB di kabupaten Tabanan memiliki sembilan belas bunyi konsonan, yaitu [p, b, m, n, t, d, r, s, c, j, $1, ?$, ), y, k, g, $\mathrm{y}, \mathrm{h}, \mathrm{w}]$. Untuk mengetahui apakah kesembilan belas bunyi konsonan itu merupakan fonem berikut ini diberikan data pasangan minimal dan pasangan mirip.

Data yang memiliki pasangan minimal:

balu [balu] 'janda' - palu [palu] 'palu' (TP $1,2,3,4)$

basang [basay] 'perut' - pasang [pasay] 'pasang' (TP 1,2,3,4)

dulang [dulan] 'tempat sesajen' - tulang [tulay] 'tulang'(TP 1,2,3,4)

udang [uday] 'udang' - utang [utay] 'hutang'(TP 1,2,3,4)

sigi [sigi] 'sumbu' - siki [siki] 'satu' (TP $1,2,3,4)$

awag [awag] 'sembrono' - awak [awa?] 'badan' (TP 1,2,4)

galak [gala?] 'galak' - galang [galan] 'terang' (TP $1,2,4)$

adek [adə?] 'cium' - adeng [adən] 'arang' (TP $1,2,4)$

patuh [patoh] 'sama' - patus [patus] 'urutan untuk upacara adat' (TP 1,2,3,4)

kaja [kaja] 'utara' - kaca [kaca] 'kaca'(TP 3)

jang [jay] 'taruh' - cang [cay] 'saya' (TP $1,2,3,4)$

baju [baju] 'baju' - banyu [ba/u] 'air beras' (TP $1,2,3,4)$

aji [aji] 'harga' - anyi [a/i] 'potong padi' (TP $1,2,3,4)$ garang [garan] 'rebut' - galang [galan] 'terang' (TP $1,2,3,4)$

saling [salın] 'saling' - saring [sarın] 'saring' (TP $1,2,3,4)$

matah [matah] mentah' - natah [natah] 'halaman' (TP 1,2,3,4)

tumi [tumi] 'anak tiri' - tuni [tuni] 'tadi' (TP $1,2,3,4)$

lawah [lawah] 'kelelawar' - layah [layah] 'lidah' (TP 1,2,3,4)

dawa [dawa] 'panjang' - daya [daya] 'malas' (TP $1,2,3,4)$

Data yang memiliki variasi bebas:

pekak [pəkak] 'kakek' - pekak [pəka?] 'kakek' (TP $1,2,4)$

Berdasarkan data pasangan minimal dan data variasi bebas di atas dapat diketahui bahwa BB di KT memiliki delapan belas fonem konsonan termasuk fonem semikonsonan /y/ dan $/ \mathrm{w} /$ dan satu alofon dari fonem /k/, yaitu [?].

\section{Distribusi Fonem-Fonem Konsonan Bahasa Bali di Kabupaten Tabanan}

Fonem / b /

Posisi awal:

bale [bale] 'balai' (TP 1,2,3,4)

baju [baju] 'baju' (TP 1,2,3,4)

Posisi tengah:

uban [uban] 'rambut yang putih' (TP 1,2,3,4)

lubak [luba?] 'musang' (TP 1,2,4)

Posisi Akhir:

urab [urab] 'aduk' (TP 1,2,3,4)

adab [adab] 'raba' (TP 1,2,3,4)

Fonem / p /

Posisi awal:

pakpak [pa?pa?] 'kunyah' (TP 1,2,4)

pegat [pəgat] 'putus' (TP 1,2,3,4)

Posisi tengah:

upas [upas] 'racun ular' (TP 1,2,3,4)

ipah [ipah] 'ipar' (TP 1,2,3,4)

Posisi Akhir:

intip [intrp] 'intip'(TP 1,2,3,4)

siap [siyap] 'ayam' (TP 1,2,4)

Fonem / m /

Posisi awal:

meme [meme] 'ibu' (TP 1,2,4)

manis [manis] 'manis' (TP 1,2,3,4)

Posisi tengah:

umah [umah] 'rumah' (TP 1,2,3,4) 
sema [səma] 'kuburan' (TP 3)

Posisi Akhir:

selem [sələm] 'hitam'(TP 1,2,3,4)

gelem [gələm] 'sakit' (TP 1,2,3,4)

Fonem / n /

Posisi awal:

nasi [nasi] 'nasi' (TP 1,2,4)

nangka [nayka] 'nangka' (TP 3)

Posisi tengah:

mani [mani] 'besok' (TP 1,2,3,4)

jani [jani] 'sekarang' (TP 1,2 3)

Posisi Akhir:

ujan [ujan] 'hujan'(TP 1,2,3,4)

demen [dəmən] 'senang' (TP 1,2,3,4)

Fonem / d /

Posisi awal:

dawa [dawa] 'panjang' (TP 3)

daki [daki] 'kotor' (TP 1,2,3,4)

Posisi tengah:

idih [idrh] 'minta' (TP 1,2,3,4)

kedis [kədis] 'burung' (TP 1,2 3)

Posisi Akhir:

ilid [ilıd] 'tersembunyi'(TP 1,2,3,4)

uled [uləd] 'ulat' (TP 1,2,3,4)

Fonem / t /

Posisi awal:

telah [təlah] 'habis' (TP 1,2, 3)

tugel [tugal] 'potong' (TP 1,2,3,4)

Posisi tengah:

mati [mati] 'mati' (TP 1,2,3,4)

orta [orta] 'berita' (TP 3)

Posisi Akhir:

kulit [kulıt] 'kulit'(TP 1,2,3,4)

lilit [lilit] 'dililit' (TP 1,2,3,4)

Fonem / s /

Posisi awal :

sampi [sampi] 'sapi' (TP 1,2, 3)

seduk [sədv?] 'lapar' (TP 1,2,4)

Posisi tengah:

base [base] 'sirih' (TP 1,2,4)

rase [rase] 'musang' (TP1,2,3)

Posisi Akhir:

batis [batıs] 'kaki'(TP 1,2,3,4)

alus [alos] 'halus' (TP 1,2,3,4)

Fonem / r /

Posisi awal:

rame [rame] 'ramai' (TP 1,2,3) rasa [rasa] 'rasa' (TP 3)

Posisi tengah:

paras [paras] 'paras' (TP 1,2,3,4)

orta [orta] 'berita' (TP 3)

Posisi Akhir:

umur [umur] 'umur'(TP 1,2,3,4)

kelor [kelør] 'nama tumbuhan' (TP 1,2,3,4)

Fonem / $1 /$

Posisi awal : layu [layu] 'layu' (TP 1,2, 3)

lubak [luba?] 'musang' (TP 1,2,4)

Posisi tengah:

telah [təlah] 'habis' (TP 1,2, 3

kulit [kulit] 'kulit'(TP 1,2,3,4)

Posisi Akhir:

godel [gədel] 'anak sapi'(TP 1,2,3,4)

tugel [tugal] 'potong' (TP 1,2,3,4)

Fonem / k /

Posisi awal:

kuku [kuku] 'kuku' (TP 1,2, 3)

kutu [kutu] 'kutu' (TP 1,2,3,4)

Posisi tengah:

daki [daki] 'kotor' (TP 1,2, 3)

jukut [jukut] 'sayur'(TP 1,2,3,4)

Posisi Akhir:

carik [carık] 'sawah'(TP 1,2,3,4)

katak [kata?] 'kodok' (TP 1,2,4)

Fonem / g /

Posisi awal:

guli [guli] 'kelereng' (TP 1,2, 3)

gabah [gabah] 'gabah' (TP 1,2,4)

Posisi tengah:

tugel [tugəl] 'potong' (TP 1,2,3,4)

gigi [gigi] 'gigi'(TP 1,2,3,4)

Posisi Akhir:

berag [borag] 'kurus'(TP 1,2,3,4)

tumbeg [tombəg] 'cangkul'(TP 1,2,3,4)

Fonem / $\mathrm{y} /$

Posisi awal:

ngaap [naap] 'perih' (TP 1,2,3)

ngaas [yaas] 'bau keringat' (TP 1,2,4)

Posisi tengah:

inget [inot] 'ingat' (TP 1,2,3,4)

inguh [invh] 'gelisah'(TP 1,2,3,4)

Posisi Akhir:

jagung [jagon] 'jagung'(TP 1,2,3,4)

tulang [tulan] 'tulang'(TP 1,2,3,4) 
Fonem / h /

Posisi awal: -

Posisi tengah:

rahayu [rahayu] 'selamat' (TP 1,2,3,4)

Posisi Akhir:

inguh [inoh] 'gelisah'(TP 1,2,3,4)

umah [umah] 'rumah'(TP 1,2,3,4)

Fonem / j /

Posisi awal:

jaja [jaja] 'jajan' (TP 3)

jagung [jagon] 'jagung' (TP 1,2,3,4)

Posisi tengah:

kija [kijə] 'kemana' (TP 1,2,4)

baju [baju] 'baju'(TP 1,2,3,4)

Posisi Akhir: -

Fonem / c /

Posisi awal:

cucu [cucu] 'cucu' (TP1,2,3)

cunguh [cuyoh] 'hidung' (TP 1,2,3,4)

Posisi tengah:

kaca [kacə] 'kaca' (TP 1,2,4)

macan [macan] 'harimau'(TP 1,2,3,4)

Posisi Akhir: -

Fonem / ) /

Posisi awal:

nyuh [)oh] 'kelapa' (TP 1,2, 3)

nyeh [əh] 'takut' (TP 1,2,4)

Posisi tengah:

anyar [a/ar] 'baru' (TP 1,2,3,4)

benyah [bə/ah] 'hancur'(TP 1,2,3,4)

Posisi Akhir: -

Fonem / w /

Posisi awal:

wani [wani] 'nama buah' (TP 1,2, 3)

wadah [wadah] 'tempat' (TP 1,2,4)

Posisi tengah:

bawang [baway] 'bawang' (TP 1,2,3,4)

tawang [taway] 'tahu'(TP 1,2,3,4)

Posisi Akhir: -

Fonem / y /

Posisi awal:

yeh [ych] 'nama buah' (TP 1,2,3)

yuyu [yuyu] 'ketam' (TP 1,2,3,4)

Posisi tengah:

layah [layah] 'lidah' (TP 1,2,3,4)

layu [layu] 'layu'(TP 1,2,3,4)

Posisi Akhir: -
Fonem-fonem konsonan di atas ada yang berdistribusi lengkap atau pun tidak lengkap. Hal yang sama juga terjadi dalam BB baku. Fonem / c, j, n, w, dan y / tidak pernah memduduki distribusi akhir, sedangkan fonem / h / tidak pernah menduduki posisi awal. Pada posisi tengan fonem $/ \mathrm{h} /$ juga kurang produktif atau sangat terbatas pemakaiannya.

Bunyi [?] pada titik pengamatan 1, 2 dan 4 pada posisi akhir sangat produktif, sedangkan di titik pengamatan 3 tidak ada. Sebaliknya bunyi $[\mathrm{k}]$ pada posisi akhir sangat produktif di titik pengamatan 3 dan tidak ada pada titik pengamatan lainnya. Meskipun kedua bunyi tersebut produktif di tempat yang berbeda, tetapi kedua bunyi itu merupakan satu fonem, yaitu fonem / $\mathrm{k} /$ dengan alofon [?]. Perbedaan realisasi kedua bunyi itu dapat diamati melalui peta berikut.

Variasi distribusi fonem / $\mathrm{k} /$ dapat dibagi menjadi dua, yaitu Klas I dan Klas II. Klas I yaitu daerah-daerah yang memiliki bunyi $[\mathrm{k}]$ pada distribusi akhir, sedangkan Klas II merupakan daerah-daerah yang mempunyai bunyi [?] pada posisi akhir. Variasi ini dapat diperjelas dengan pemetaan berikut.

Gambar 2. Peta variasi realisasi \& distribusi fonem kon. / k/

f Klas I [k]

Klas I [k]

Klas II [?]

\section{SIMPULAN}

Berdasarkan analisis dan pemetaan di atas, dapat disimpulan bahwa variasi fonologis adalah variasi dalam bidang realisasi fonem dan dalam bidang distribusi fonem. Fonem $/ \partial /$ pada posisi akhir terbuka dalam BB di kabupaten Tabanan memiliki dua buah realisasi yaitu bunyi [a] dan bunyi [ə]. Tiap-tiap bunyi tersebut memiliki areal yang berbeda. Bunyi [ə] terdapat di TP 1,2,4 dan bunyi [a] terdapat di titik pengamatan 3 .

Fonem /e/ dan /o/ pada posisi akhir terbuka masing-masing memiliki dua buah variasi. Fonem /e/ realisasinya [e] dan $[\varepsilon]$, sedangkan fonem $/ \mathrm{o} /$ realisasinya [o] dan [0]. Bunyi [e] dan [o] terdapat di titik pengamatan 1,2,4 dan bunyi $[\varepsilon]$ dan $[0]$ terdapat pada TP 3 . 
Di samping perbedaan realisasi fonem vokal, terdapat pula perbedaan realisasi fonem konsonan $/ \mathrm{k} /$. Fonem $/ \mathrm{k} /$ direalisasikan dengan [k] dan [?]. Bunyi [k] direalisasikan pada TP 3, sedangkan [?] direalisasikan pada TP 1,2,4.

Pada TP 1,2,4 tidak memiliki fonem /a/ pada distribusi akhir, sedangkan TP 3 memiliki distribusi /a/ yang lengkap. Pada daerah yang memiliki fonem /a/ distribusi lengkap tidak dikenal bunyi [ə] pada distribusi akhir. Pada daerah-daerah yang memiliki fonem /a/ berdistribusi tidak lengkap bunyi [ə] justru berdistribusi lengkap.

Bunyi [k] pada distribusi akhir tidak dikenal pada titik pengamatan 3 , bunyi itu hanya dikenal pada distribusi terakhir pada TP $1,2,4$. Bunyi [?] pada distribusi akhir dikenal pada TP 1,2,4 dan tidak dikenal pada distribusi akhir pada TP 3 .

\section{DAFTAR PUSTAKA}

Ayatrohaedi. (1979). Dialektologi: sebuah pengantar. Pusat Pembinaa dan Pengembangan Bahasa Departemen Pendidikan dan Kebudayaan.

Bagus, I. G. N. (ed). (1975). Masalah pembakuan Bahasa Bali. Bahasa Bali/Pesamuan Agung Basa Bali.

Jendra, I Wayan, dkk. (1977). Morfologi bahasa Bali.

Sudaryanto. (1982). Metode Linguistik. Fakultas Sastra dan Kebudayaan Universitas Gajah Mada.

Sudaryanto. (1988). Metode Linguistik Bagian kedua Metode dan Aneka Teknik Pengumpulan Data. Penerbit Sabda.

Sudaryanto. (2015). Metode dan Aneka Teknik Analisis Bahasa. Gajah Mada University Press.

Thoir, N., \& Simpen, \& I. W. (1987). Ilmu Bahasa Indonesia Fonologi. CV Kayumas. 